\title{
Lost in translation? Insights into caribou habitat selection from forest inventory data
}

\author{
Tyler D. Rudolph ${ }^{a}$, Doug MacNearney ${ }^{b \dagger}$, and Laura Finnegan ${ }^{b *}$ \\ ${ }^{a}$ Rudolph Expertise, Montreal, QC H4E 3C8, Canada; ${ }^{b}$ Caribou Program, fRI Research, 1176 Switzer \\ Drive, Hinton, AB T7V 1V3, Canada \\ *lfinnegan@friresearch.ca \\ ${ }^{\dagger}$ Current address: Wildlife Research Division, Environment and Climate Change Canada, National Wildlife \\ Research Centre, Ottawa, ON K1S 5B6, Canada.
}

\begin{abstract}
The gap between research and its implementation is an impediment to conservation of the environment. Translating science into actionable management and policy requires effective communication and collaboration among scientists, practitioners, and policy-makers. Ecologists routinely rely on spatial data to describe wildlife distributions; however, habitat definitions vary by species, and data sources often differ from those used by land managers. Finding commonalities in the language and data used to plan for industrial activities and wildlife conservation may help address the researchimplementation gap for threatened species like woodland caribou. We built resource selection functions for caribou using Alberta Vegetation Index (AVI) habitat data, which is employed by the Alberta forest industry for landbase planning. Our goal was to bridge the research-implementation gap by providing the forest industry with tools to facilitate planning for caribou conservation within their jurisdiction. In contrast to previous studies that highlighted shortcomings in AVI data for predicting wildlife habitat use, we found that resource selection function models that combined AVI data with complementary covariates validated well to predict caribou habitat use. We suggest that by using a data source familiar to land managers, ecologists can facilitate the bridging of the researchimplementation gap without compromising the quality of ecological modeling.
\end{abstract}

Citation: Rudolph TD, MacNearney D, and Finnegan L. 2019. Lost in translation? Insights into caribou habitat selection from forest inventory data. FACETS 4: 531-550. doi: 0.1 | 39/facets-20 | 8-0050

Handling Editor: Jeremy Kerr

Received: December 12, 2018

Accepted: July 8, 2019

Published: October 17, 2019

Copyright: (C) 2019 Rudolph et al. This work is licensed under a Creative Commons Attribution 4.0 International License (CC BY 4.0), which permits unrestricted use, distribution, and reproduction in any medium, provided the original author(s) and source are credited.

Key words: caribou, forest inventory, Alberta, implementation, habitat selection, habitat management

\section{Introduction}

The research-implementation gap is an impediment to effective conservation and management of the environment (Cash et al. 2003; Weichselgartner and Kasperson 2010). Barriers to the implementation of research in applied settings include mismatch between data produced from research and the information needed by practitioners or policy-makers, difficulties interpreting and communicating scientific results, and lack of resources or feasible plans to drive implementation of scientific results (Arlettaz et al. 2010; Cook et al. 2013). Translating science into actionable management and policy requires effective communication and collaboration among scientists, practitioners, and policymakers (i.e., translational ecology; Sutherland et al. 2011; Enquist et al. 2017; Hallett et al. 2017 or boundary science; Cook et al. 2013).

Published by: Canadian Science Publishing 
In planning conservation efforts, mitigation of human impacts, and adaptive management, ecological research is an essential means of linking habitat to species use and occurrence in a spatial framework (Margules and Pressey 2000; Pressey et al. 2007; de Groot et al. 2010). In recent years, use of satellitederived habitat data to understand associations between species and habitat and for spatial planning has increased along with the availability of high-resolution satellite images that are accurate across large areas, updated regularly, and often freely available (e.g., Warren et al. 2014; Bleyhl et al. 2017; Hofmann et al. 2017; Tucker et al. 2018). However, despite many advantages, the satellite-derived habitat data used by scientists often do not meet the specific needs of practitioners and therefore could be a barrier between science and implementation. This mismatch in data is particularly notable in the forest sector where management is largely based on inventory data derived from a combination of aerial photo interpretation and field visits (McDermid et al. 2009; Päivinen et al. 2009). Forest inventory data provide detailed information required for harvest management, specifically, information on stand attributes and tree species that is often obscured from satellite-derived habitat data (but see Gastón et al. 2017). However, despite being tailored for use by the forest sector, forest inventory data can be challenging to integrate into ecological models due to inconsistencies between jurisdictions (but see Gillis et al. 2005; Gschwantner et al. 2016), mismatches between spatial and temporal coverage for wide-ranging species (e.g., alpine and northern areas; Johnson et al. 2003; McDermid et al. 2009; Maxie et al. 2010; Imbeau et al. 2015), and disjunction between forest resource inventory attributes and ecological function for wildlife species (McLaren and Mahoney 2001; Johnson et al. 2003; McDermid et al. 2009; Boan et al. 2013). Satellite-derived habitat data are the better choice for spatial models, particularly when the goal is a map or probability surface or where the area of interest is large or crosses jurisdictional boundaries. However, at a fine scale, integration of forest resource inventory data into ecological models represents a significant opportunity to lessen the researchimplementation gap. Indeed, successful application of forest inventory data to model and predict species distribution and use would facilitate the implementation of research findings into concrete management actions and thereby serve to bridge the research-implementation gap.

Across the boreal forest of Canada, the forest sector is under increasing pressure to implement sustainable forest management that considers biodiversity and species at risk (Brown et al. 2007; Canadian Council of Forest Ministers 2014). Of particular concern in recent years are woodland caribou, Rangifer tarandus caribou, which are declining across their range and listed as threatened under the Canadian Species at Risk Act. Woodland caribou (hereafter caribou) require large tracts of intact mature forest to maintain a low spatial overlap with predators (Bergerud et al. 1990; DeCesare et al. 2010). Habitat disturbance within caribou ranges, including forest harvesting, has altered predatorprey dynamics by increasing the spatial overlap between caribou and ungulates that prefer early seral forest, which in turn has increased the spatial overlap between caribou and shared predators (DeCesare et al. 2010), increased predation risk for caribou (DeCesare et al. 2014), and resulted in widespread caribou declines (Vors and Boyce 2009; Festa-Bianchet et al. 2011; Hervieux et al. 2013). Caribou are arguably of greatest concern in the province of Alberta, and there is immediate pressure on the forest sector to adapt harvesting strategies to maintain caribou populations (Environment Canada 2012, 2014; Government of Alberta 2017). Although resource selection function probability surfaces for caribou in Alberta are available (DeCesare et al. 2012; Slater 2013), and the relationship between caribou and satellite-derived habitat data in Alberta is well understood (e.g., Neufeld 2006; DeCesare et al. 2012; Johnson et al. 2015), habitat categories such as "closed conifer" are too coarse for forest practitioners who make management plans using fine-scale stand information (e.g., height, age, and leading species) and may be impeding the ready translation of scientific results into practical solutions for caribou conservation. With the exception of one study in the northeast of the province (Latham et al. 2013) and two short-term studies in west-central Alberta (Szkorupa and Schmiegelow 2003; Saher and Schmiegelow 2005), there are no detailed multi-year assessments of caribou response to habitat described using the provincial standard for forest inventory data, the 
Alberta Vegetation Inventory (AVI; Alberta Sustainable Resource Development 2005), in the peerreviewed literature. Recognizing that caribou conservation is a multi-faceted problem with social, ecologic, and economic implications, we suggest that one way to bridge the research-implementation gap in this context is to use forest resource inventory data to evaluate caribou response to habitat in a way that is easy to integrate into existing forest management planning in Alberta.

Driven by needs of the forest sector to understand the relationship between caribou and habitat described using forest inventory data, our goal was to leverage caribou Global Positioning System (GPS) data collected between 1998 and 2015 to describe habitat selection in west-central Alberta using the AVI. To avoid some of the drawbacks of using AVI data (i.e., decreased accuracy across larger geographic scales, combining multiple datasets of different ages, and lower classification accuracy within mixed and broadleaf stands (McDermid et al. 2009)), we focused our study within a coniferdominated $3700 \mathrm{~km}^{2}$ portion of west-central Alberta that was managed by Weyerhaeuser Co. Ltd. Grande Prairie under a forest management agreement (FMA) with the Government of Alberta, an area containing the winter ranges of two central mountain caribou herds. Our specific objective was to assess whether caribou responded differently to stands defined using AVI attributes stand origin (natural (i.e., fire) versus harvested), regeneration height, and canopy closure. Results of this research will permit forest managers to directly evaluate the impact of harvest management strategies on the probability of caribou occurrence in their FMA and, in doing so, facilitate bridging of the researchimplementation gap by emphasizing habitat categories readily utilized by the forest industry.

\section{Methods}

\section{Study area}

The study took place in west-central Alberta, Canada, and included the portion of the Weyerhaeuser Co. Ltd. Grande Prairie (hereafter Weyerhaeuser) FMA that intersects the Redrock-Prairie Creek and Narraway provincial caribou ranges (Fig. 1). Redrock-Prairie Creek and Narraway caribou are part of the central mountain caribou designated unit (COSEWIC 2011) and migrate between high-elevation summer range in alpine and subalpine habitat and low-elevation winter range in the foothills (Edmonds and Bloomfield 1984; Brown and Hobson 1998; COSEWIC 2014). Thirty-five percent of Redrock-Prairie Creek and 28\% of Narraway ranges fall within parks and protected areas, with industrial development concentrated in the foothills to the east of the continental divide. Oil and gas activities first occurred in the 1950s and a coal mine has been operating in the eastern portion of the Redrock-Prairie Creek range since 1969. Forestry operations have been ongoing since the 1980s (Smith et al. 2000). In 2012 the Redrock-Prairie Creek and Narraway herds were estimated at 127 and 72 individuals, respectively, and are listed as endangered by COSEWIC (2014).

\section{GPS telemetry data}

Adult female caribou in the Redrock-Prairie Creek and Narraway herds were captured using aerial net guns between 1999 and 2015 and fitted with GPS telemetry collars (Lotek Engineering, Newmarket, Ontario). Collaring was conducted as part of a long-term collaborative effort between Weyerhaeuser and Alberta Environment and Parks, and it adhered to the Government of Alberta's Animal Care Protocol No. 008 (Hervieux et al. 2013). Collars were programmed to collect 4-12 locations per day, depending on the year and model of the collar. We retained GPS telemetry locations for analysis if the recorded dilution of precision was $<10$ (Dussault et al. 2001; Lewis et al. 2007). To account for dynamics in the spatial distribution of caribou throughout the year, we assigned each location to one of six seasons (spring, calving, summer, fall, early winter, or late winter) based on inflection points in daily movement rates that indicate movement between seasonal ranges and transition dates between seasons (Rudolph and Drapeau 2012; MacNearney et al. 2016). Redrock-Prairie Creek and Narraway caribou make an annual migration between foothills (winter) and alpine (summer) habitat; 


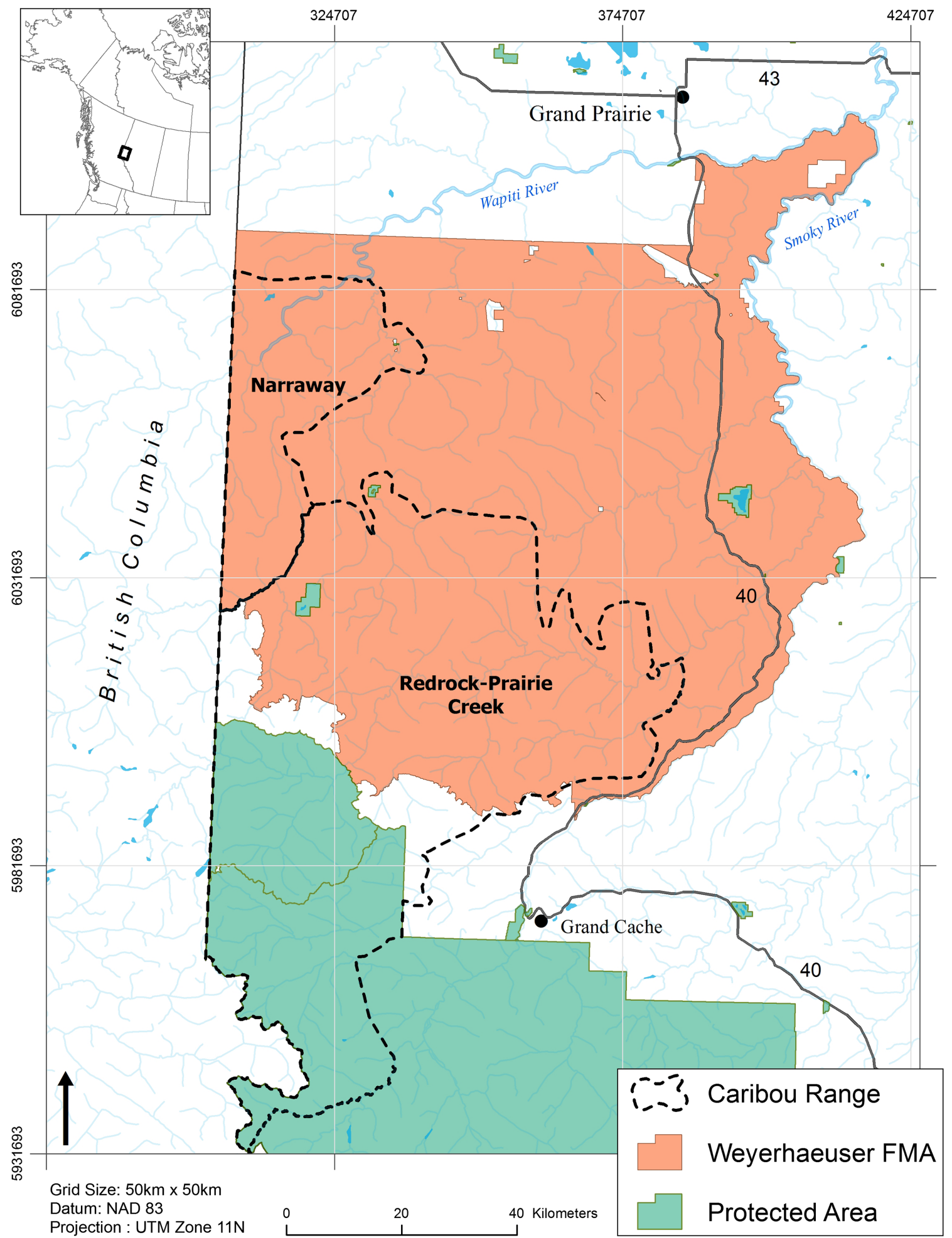

Fig. 1. Study area map showing provincially designated range boundaries of the Redrock-Prairie Creek and Narraway central mountain caribou herds and the Weyerhaeuser Grande Prairie forest management agreement (FMA) boundary in west-central Alberta, Canada. Figure was produced using ArcGIS 10.3.1 using Government of Alberta 20k base features. 
however, as this study was limited to areas within the Weyerhaeuser Grande Prairie FMA boundaries, we only retained animals with $>80 \%$ of locations within the FMA by season for subsequent analyses. This approach limited our analysis to the early winter (29 November to 4 February) and late winter ( 5 February to 5 May) seasons. The final telemetry data set consisted of 61824 locations from 53 individuals in the Redrock-Prairie Creek herd (15 496 early winter; 46328 late winter) and 23818 locations from 24 individuals in the Narraway herd (9874 early winter; 13944 late winter).

\section{AVI habitat data and additional landscape data}

We used AVI data provided by Weyerhaeuser that was developed for the 2011 iteration of their decadal forest management plan. These data included the age, dominant species, height, and canopy closure for forested habitats derived from 2005 aerial photo interpretation. To build annual data that accounted for changes in tree height between 1998 and 2015, we used the Growth and Yield Projection System (GYPSY) developed by Huang et al. (2010) to calculate site indices based on tree age and height, and subsequently we used these indices to predict annual heights of stands. An important caveat in considering the GYPSY height models is that because top height (height of 100 fattest trees/stand) was not available for all stands, we instead used photo-interpreted stand height, which has an error margin of $\pm 3 \mathrm{~m}$. For data analysis, we pooled habitats derived from the AVI data into 18 classes considered pertinent to forestry operations and habitat selection by caribou (Table 1; Table S1). The proportions of each class present in the Redrock-Prairie Creek and Narraway ranges within the Weyerhaeuser FMA boundary are summarized in Table S2. For data analysis we chose open canopy coniferous forest of natural origin as our reference condition because it was the most prevalent habitat type in the FMA (Table \$2).

Previous research found that forest inventory data alone was insufficient to characterize wildlife habitat selection (McDermid et al. 2009; Boan et al. 2013), and that caribou habitat use is dependent on the inter-relationships among habitat, terrain, and disturbance within seasonal ranges (DeCesare et al. 2012). To account for the response of caribou to other features on the landscape, we therefore included a suite of additional covariates describing habitat, terrain, and disturbances within our models (Table 1). For habitat covariates, we considered the distance to large streams, small streams, and the distance to the tree line (i.e., the Euclidean distance to alpine habitat as defined by MacNearney et al. (2016)). For disturbance covariates, we mapped roads using Digital Integrated Dispositions obtained from the Government of Alberta, whereas cutblock spatial data and harvest years were provided by Weyerhaeuser. Based on the findings of DeCesare et al. (2012), we used a 5-km moving window average to calculate the density of secondary roads (square-root transformed for normality) and the density of cutblock edges (cutblocks $<30$ years old) within our study area. We also considered distance to secondary roads, but because animals have been shown to respond in a nonlinear fashion to road proximity (Leblond et al. 2011), we transformed this variable using an exponential decay function (Nielsen et al. 2009). We determined the optimal decay rate parameter ( $\alpha$, range: $5 \mathrm{e}^{-4}$ to $\left.5 \mathrm{e}^{-3}\right)$ by comparing the fit of iterative univariate logistic regression models using Akaike's Information Criterion (AIC) for small sample sizes (AICc; Hurvich and Tsai 1989). Lastly, for terrain covariates, we used a 30-m resolution digital elevation model to calculate elevation, slope, north-south aspect, east-west aspect, a topographic position index (Jenness 2006), and a compound topographic index (Gessler et al. 2000; Table 1).

\section{Data analysis}

Individual home ranges and used and available points

We estimated kernel density utilization distributions (UDs) for each combination of individual caribou, season, and year using a fixed kernel method with a $100 \mathrm{~m}$ cell size and the "plug-in" method to determine the smoothing parameter $h$ (Sheather and Jones 1991; MacNearney et al. 2016). As 
Table 1. Habitat covariates used to develop second-order resource selection functions during early and late winter for Redrock-Prairie Creek and Narraway caribou within the Weyerhaeuser forest management agreement boundary in west-central Alberta, Canada, between 1998 and 2015.

\begin{tabular}{|c|c|c|c|}
\hline Covariate name & Description & Dynamic $^{a}$ & Data source \\
\hline \multicolumn{4}{|c|}{ Habitat Alberta Vegetation Inventory (AVI) } \\
\hline anthro_har & $\begin{array}{l}\text { All anthropogenic features except cutblocks; roads, well sites, pipelines, } \\
\text { mines, gravel pits; categorical }\end{array}$ & Yes & $\begin{array}{l}\text { AVI; Alberta Base Features; } \\
\text { Digital Integrated Dispositions }\end{array}$ \\
\hline cconifer_har & Closed conifer forest, all heights, harvest origin; categorical & Yes & AVI; stand index models \\
\hline cconifer_nat & Closed conifer forest, all heights, natural origin; categorical & - & - \\
\hline cpine_0_14_har & Closed pine forest $<14 \mathrm{~m}$ in height, harvest origin; categorical & - & - \\
\hline cpine_0_14_nat & Closed pine forest $<14 \mathrm{~m}$ in height, natural origin; categorical & - & - \\
\hline cpine_14_17_all & Closed pine forest $14-17 \mathrm{~m}$ in height, all origins; categorical & - & - \\
\hline cpine_18up_all & Closed pine forest $>17 \mathrm{~m}$ in height, all origins; categorical & - & - \\
\hline oconifer_har & Open conifer forest, all heights, harvest origin; categorical & - & - \\
\hline oconifer_nat ${ }^{b}$ & Open conifer forest, all heights, natural origin; categorical & - & - \\
\hline open_low_veg & Herbaceous shrublands; categorical & - & - \\
\hline opine_18up_all & Open pine forest $>17 \mathrm{~m}$ in height, all origins; categorical & - & - \\
\hline mix_dec & $\begin{array}{l}\text { Mixed-wood and deciduous forest, all heights, natural and } \\
\text { harvested origin; categorical }\end{array}$ & - & - \\
\hline water & Lakes and rivers & - & - \\
\hline wetland & Wetlands; categorical & - & - \\
\hline \multicolumn{4}{|l|}{ Habitat other } \\
\hline dist2tree & Distance $(m)$ to tree line; continuous & - & - \\
\hline dist2water_1M & Distance $(\mathrm{m})$ to nearest large watercourse; continuous & No & Alberta base features \\
\hline dist2water_20k & Distance $(\mathrm{m})$ to nearest medium watercourse; continuous & - & - \\
\hline \multicolumn{4}{|l|}{ Disturbance } \\
\hline cbe $5 \mathrm{k}$ & Density of cutblock edges within $5 \mathrm{~km}$ radius $\left(\mathrm{km} / \mathrm{km}^{2}\right)$ & Yes & $\begin{array}{l}\text { Weyerhaeuser Co. Ltd. } \\
\text { Grande Prairie }\end{array}$ \\
\hline rdist_sec_decay & $\begin{array}{l}\text { Distance to nearest secondary road }(\mathrm{m}) \text {, transformed using negative } \\
\text { exponential decay function }(f(x)=1-\exp (-0.002 \times x)\end{array}$ & - & - \\
\hline sqrt.rden_all5k & Density of all roads within $5 \mathrm{~km}$ radius $\left(\mathrm{km} / \mathrm{km}^{2}\right)$, square-root transformed & Yes & - \\
\hline \multicolumn{4}{|l|}{ Terrain } \\
\hline aspect_ns & North-south aspect; continuous from -1 to 1 & - & - \\
\hline apect_ew & East-west aspect; continuous from -1 to 1 & - & - \\
\hline cti & Compound Topographic Index; continuous & - & - \\
\hline elevation & Elevation $(\mathrm{m})$; continuous & No & $\begin{array}{l}30 \mathrm{~m} \text { resolution digital } \\
\text { elevation model }\end{array}$ \\
\hline slope & Slope $\left({ }^{\circ}\right)$; continuous & - & - \\
\hline tpi1000 & Topographic Position Index; continuous & - & - \\
\hline
\end{tabular}

${ }^{a}$ Covariates were considered "dynamic" if they changed over the time period of GPS telemetry data collection and therefore warranted inclusion on a timed landscape.

${ }^{b}$ Reference category. 
kernel density estimates are biased at small sample sizes (Blundell et al. 2001) we excluded individuals with $<50$ locations in a given season and year from analyses. We clipped each caribou home range to the Weyerhaeuser FMA boundary.

We sampled used points using each individual UD as a probability surface by which to weight a random sample. This method has several potential advantages over using telemetry locations directly: (i) used locations are not biased by spatial and temporal autocorrelation that arises from telemetry locations being collected along a trajectory of animal movement (Fieberg et al. 2010), (ii) used locations sampled from the UD are not biased by occasional missed fixes that may occur from dense overstory or high movement speeds by animals (Dussault et al. 1999), and (iii) sampling used locations from the UD allows a balanced sample for each individual (Frair et al. 2004). We sampled 775 used locations per individual and season; they were proportional to the mean number of telemetry locations collected per individual per season. Available points should be sampled at a geographic scale appropriate to the scale of selection under investigation (Johnson 1980; DeCesare et al. 2012). As we were interested in selection of home ranges within the population range, we sampled available points randomly from the intersection of the Weyerhaeuser FMA and the provincially designated herd ranges for Redrock-Prairie Creek and Narraway caribou (see Fig. 1). We sampled available points at a ratio of five available points per used point to ensure coefficient stability (Northrup et al. 2013).

\section{Resource Selection Function (RSF) modeling using AVI data}

We modeled caribou space use using mixed-effects logistic regression (Gillies et al. 2006). As the model data contained five times more "available" than "used" locations, and $17 \%$ of individuals $(n=13)$ were observed for two consecutive years, we assigned a random intercept to each collared animal and animal-year combination. Random intercepts assign a uniform serial correlation structure to nested groups of observations, thereby producing unbiased parameter estimates (Zuur et al. 2009). We conducted all analyses and visualized results using the R software ( $\mathrm{R}$ Development Core Team 2017), packages "lme4" (Bates et al. 2015) and "ggplot2" (Wickham 2016).

We developed a series of candidate models consisting of covariates associated with environmental attributes influencing caribou space use according to the scientific literature (e.g., DeCesare et al. 2012; Table 1). Before building models we scaled and centered all continuous covariates to facilitate model convergence. We grouped covariates by category (Table 1) and compared the null hypothesis (i.e., no selection by caribou) with candidate models comprising terrain, habitat, disturbance, and combinations thereof (Table 2). We ranked candidate models using Akaike's information criterion for small sample sizes (AICc; Hurvich and Tsai 1989) and identified the final most parsimonious $\operatorname{model}(\mathrm{s})$ as the model(s) with the smallest AICc and the highest model weight $\left(\omega_{i}\right)$.

We used variance inflation factors (VIFs) to control for multicollinearity arising from correlation between predictor covariates. We began with the full model (all covariates) and sequentially removed covariates with the highest VIF, recalculating and repeating this procedure until VIFs for all covariates were below 3 (Zuur et al. 2010). We present results as beta coefficients and odds ratios ( $\exp \beta$; OR), with corresponding lower and upper $95 \%$ confidence intervals. For continuous covariates, ORs are the odds of caribou selection attributed to a single unit increase in a covariate when compared to a reference condition (covariate $=0$ ) and remain constant across predictor values. When predictors are categorical, ORs are the odds of caribou selecting one condition over a specified reference condition (Grimes and Schulz 2008).

\section{Model validation}

We assessed the predictive accuracy of final RSF models using k-fold cross-validation (Boyce et al. 2002). In five separate iterations, we withheld $20 \%$ of used observations from the dataset, fitted the 
Table 2. Candidate models used to build second order early and late winter resource selection functions for the Narraway and Redrock-Prairie Creek caribou herds within the Weyerhaeuser Grande Prairie forest management agreement boundary in west-central Alberta, Canada, between 1998 and 2015.

\begin{tabular}{|c|c|}
\hline Model & Model formula \\
\hline null & use_avail $\sim 1+(1 \mid \mathrm{id} / \mathrm{yr})$ \\
\hline veg & $\begin{array}{l}\text { use_avail } \sim \text { anthro_har }{ }^{a}+\text { opine_0_14_har }+ \text { cconifer_nat }+ \text { opine_0_14_nat }+ \\
\text { cconifer_har }{ }^{a}+\text { opine_18plus_all }+ \text { oconifer_har }+ \text { wetland }+ \text { cpine_18plus_all }+ \\
\text { opine_14_18_all }+ \text { water }+ \text { cpine_0_14_har }+ \text { cpine_14_18_all }+ \text { cpine_0_14_nat }+ \\
\text { open_low_veg }+ \text { mix_dec }+(1 \mid \text { id } / y r)\end{array}$ \\
\hline terrain & $\begin{array}{l}\text { use_avail } \sim \text { dem }+ \text { dist } 2 \text { tree }{ }^{b}+\text { dist } 2 \text { water } 1 \mathrm{M}+\mathrm{cti}+\text { tpi1 } 1000+\text { dist } 2 \text { water } 20 \mathrm{k}+ \\
\text { slope }+ \text { aspect_ns }+ \text { aspect_ew }+(1 \mid \mathrm{id} / \mathrm{yr})\end{array}$ \\
\hline anthro & $\begin{array}{l}\text { use_avail } \sim \text { anthro_har }{ }^{a}+\text { opine_0_14_har }+ \text { cconifer_har }^{a}+\text { oconifer_har }+ \\
\text { cpine_0_14_har }+ \text { cbe5k }+ \text { sqrt.rden_all5k } \mathrm{k}^{b}+\text { rdist_sec.decay }+(1 \mid \mathrm{id} / \mathrm{yr})\end{array}$ \\
\hline vegterrain & $\begin{array}{l}\text { use_avail } \sim \text { cpine_14_18_all + wetland + opine_18plus_all }+ \text { anthro_har }^{a}+ \\
\text { opine_0_14_nat }+ \text { cpine_0_14_nat }+ \text { cconifer_nat }+ \text { cconifer_har }{ }^{a}+ \\
\text { opine_14_18_all + water }+ \text { oconifer_har }+ \text { cpine_18plus_all }+ \text { opine_0_14_har }+ \\
\text { mix_dec }+ \text { cpine_0_14_har }+ \text { open_low_veg }+ \text { dem }+ \text { dist } 2 \text { tree }{ }^{b}+\text { dist } 2 \text { water } 1 \mathrm{M}+ \\
\text { cti }+ \text { tpi1000 + dist2water20k }+ \text { slope }+ \text { aspect_ns }+ \text { aspect_ew }+(1 \mid \mathrm{id} / \mathrm{yr})\end{array}$ \\
\hline full & 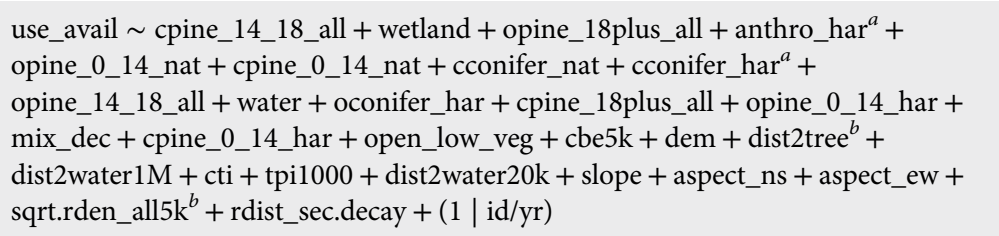 \\
\hline
\end{tabular}

Note: Covariates are described in Table 1.

${ }^{a}$ Excluded from Narraway models due to insufficient sample sizes.

${ }^{b}$ Excluded from Narraway models due to excessive multicollinearity.

model with the remaining ("training") data, and used the resulting fitted model to calculate predicted RSF values for the withheld ("validation") observations. We then partitioned predicted values from training and validation datasets into identical area-adjusted bins and compared values within each bin using Spearman's rank correlation coefficient $\left(r_{s}\right)$, where $r_{s}$ values closer to one indicate better predictive ability of the final model.

\section{Results}

Because of excessive multicollinearity with other variables (VIF $>3$ ), we excluded distance to tree line and road density from candidate models fitted to data from the Narraway range. We also excluded cutblocks, previously harvested closed canopy coniferous forest, and the "other" categories from Narraway data sets because of the complete absence of "used" observations. For both seasons and herds, according to AICc, the full model including AVI, terrain, and disturbance parameters was the most parsimonious $\left(\omega_{i}=1\right)$ and better at explaining caribou habitat selection than the models including AVI and terrain combined, or models including only terrain, AVI, or disturbance parameters (Tables S3 and S4). As the goal of our study was to describe caribou habitat selection using forest inventory habitat data, only responses of caribou to AVI-derived habitat are described in detail here. Complete model parameters are in Tables S5 and S6.

During early winter, in comparison to the reference category, Redrock-Prairie Creek caribou were more likely to select harvest-origin open pine stands up to $14 \mathrm{~m}$ in height, natural-origin closed pine 
stands up to $14 \mathrm{~m}$ in height, pine stands between 14 and $18 \mathrm{~m}$ in height regardless of canopy cover or stand origin, wetlands, and anthropogenic features besides cutblocks (Fig. 2). During early winter, in comparison to the reference category, Redrock-Prairie Creek caribou were less likely to select open and closed pine stands $>18 \mathrm{~m}$ in height regardless of stand origin and were less likely to select closed conifer and mixed deciduous stands, previously harvested open conifer stands, and shrub and herb (Fig. 2). During late winter, in comparison to the reference category, Redrock-Prairie Creek caribou were less likely to select open conifer stands, anthropogenic features other than cutblocks, and open pine stands regardless of stand origin or height. During early and late winter, Redrock-Prairie Creek caribou were also more likely to select areas further from roads (early-winter OR 1.23; late winter OR 1.37), areas further from the tree line (early-winter OR 1.77; late winter OR 1.22), and areas

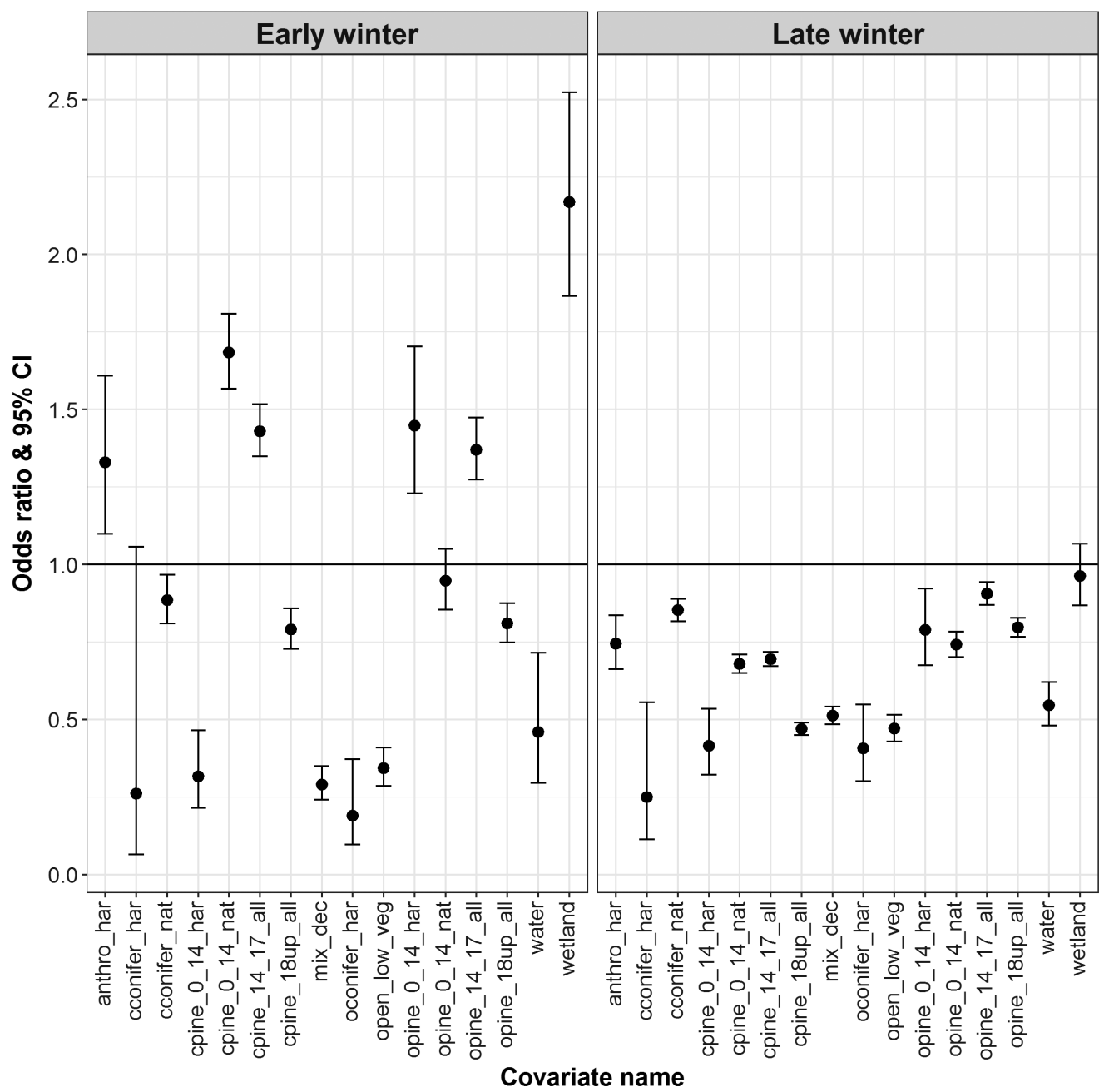

Fig. 2. Odds ratios and $95 \%$ confidence intervals for final models describing second order early and late winter resource selection functions for the Redrock-Prairie Creek caribou herd within the Weyerhaeuser Grande Prairie forest management agreement boundary in west-central Alberta, Canada, between 1998 and 2015, using Alberta Vegetation Inventory habitat data. Odds ratios $>1$ (horizontal black line) indicate that a habitat was selected more than the reference category (natural-origin open conifer, oconifer_nat), while odds ratios $<1$ indicate that a habitat was selected less than the reference category. Complete model parameters are in Table S5. Covariates are described in Table 1. 
at higher elevations, with the latter especially important during early winter (early-winter OR 4.30; late winter OR 1.62; Table S5).

During early winter, in comparison to the reference category, Narraway caribou were more likely to select natural-origin open pine stands up to $14 \mathrm{~m}$ in height and open pine stands between 14 and $17 \mathrm{~m}$ in height, but were less likely to select harvest-origin pine stands $<14 \mathrm{~m}$ in height, closed pine stands $>14 \mathrm{~m}$ in height, open pine stands $>18 \mathrm{~m}$ in height, harvest-origin open conifer stands, and natural-origin closed conifer stands (Fig. 3). During late winter, in comparison to the reference category, Narraway caribou were more likely to select natural-origin open pine stands up to $14 \mathrm{~m}$ in

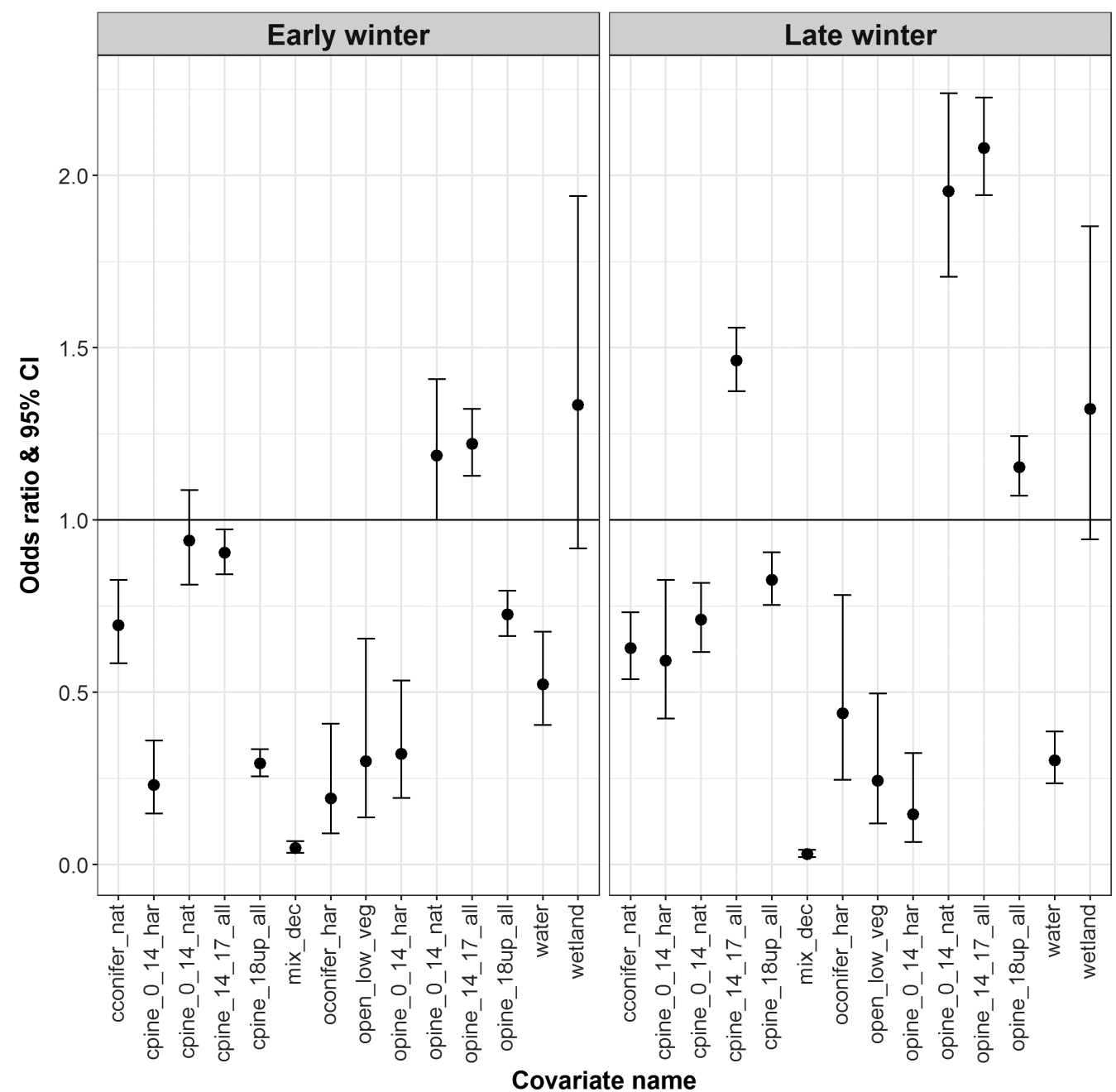

Fig. 3. Odds ratios and $95 \%$ confidence intervals for final models describing second order early and late winter resource selection functions for the Narraway caribou herd within the Weyerhaeuser Grande Prairie forest management agreement boundary in west-central Alberta, Canada, between 1998 and 2015, using Alberta Vegetation Inventory habitat data. Odds ratios $>1$ (horizontal black line) indicate that a habitat was selected more than the reference category (natural-origin open conifer, oconifer_nat), while odds ratios $<1$ indicate that a habitat was selected less than the reference category. Complete model parameters are in Table S6. Covariates are described in Table 1. 
height, and regardless of stand origin were more likely to select open pine stands $>14 \mathrm{~m}$ in height and closed pine stands between 14 and $18 \mathrm{~m}$ in height. During late winter, Narraway caribou were less likely to select harvest-origin open pine stands $<14 \mathrm{~m}$ in height, closed pine stands $<14 \mathrm{~m}$ in height and $>18 \mathrm{~m}$ in height, natural-origin closed conifer stands, and harvest-origin open conifer stands (Fig. 3). During early and late winter Narraway caribou were also less likely to select mixed deciduous stands and shrub and herb (Fig. 3). Narraway caribou were also more likely to select areas further from roads (early winter OR 1.04; late winter OR 1.56) and streams (early winter OR 1.32; late winter OR 1.04), areas with lower densities of cutblock edges (early winter OR 0.22; late winter OR 0.19), areas at high elevations during early winter (OR 1.59), and areas at lower elevations during late winter (OR 0.94; Table S6). K-fold cross-validation indicated strong predictive power of final models (Redrock-Prairie Creek early winter mean $r_{s} 0.981$, late winter mean $r_{s} 0.982$; Narraway early winter mean $r_{s} 0.931$, late winter mean $r_{s} 0.898$; Table S7).

\section{Discussion}

To effectively bridge the research-implementation divide, practitioners need data and analyses that can be directly translated into management actions. Across the boreal forest of Canada the resource sector, including forestry, is under pressure to maintain or restore ecosystem function for caribou (Environment Canada 2012, 2014), yet few results are available that directly link caribou habitat use to fine-scale forest inventory data. By combining multi-year caribou GPS and forest inventory data we found that stand origin, tree height, tree species, and canopy cover influenced habitat use by caribou at the coarse-scale during winter, but that habitat use differed between herds, and changed across the winter season. Generally, caribou preferred conifer stands, specifically open canopy stands (canopy cover $<50 \%$ ), and during early winter shorter, open and closed pine stands were preferred over open conifer stands. Our results, combined with previous research (Leblond et al. 2011; DeCesare et al. 2012), suggest that caribou select a mosaic of stand types during the winter season, which may be mediated by trade-offs by caribou to enhance access to winter forage, and reduce spatial overlap with predators (McLoughlin et al. 2010; DeCesare et al. 2014). However, our study is also unique, because by using forest inventory data combined with 17 years of caribou GPS data, our analysis revealed additional insights into the stand attributes selected by caribou, which were not apparent from previous work in our study area (DeCesare et al. 2012; Johnson et al. 2015).

During winter, in accordance with previous research, we found that caribou generally selected older and moderate to open canopy cover stands, and they avoided mixed stands and early seral habitat (e.g., Fortin et al. 2008; Leblond et al. 2011; DeCesare et al. 2012; Losier et al. 2015), likely to reduce their predation risk (Courbin et al. 2009; Ehlers et al. 2016) and maximize their access to terrestrial and arboreal lichens, important winter forage (Vitt et al. 1988; Coxson and Marsh 2001; Szkorupa and Schmiegelow 2003). However, we also found caribou selected pine stands regardless of stand age or canopy cover. It is possible that by selecting open and closed pine stands throughout the winter, caribou are mitigating their exposure to predation by wolves, which may also select open lichen forest (Leblond et al. 2011). Caribou may also be altering their habitat use to maximize access to forage in response to fine-scale weather patterns (i.e., snowfall) and increasing snow accumulation throughout the winter as denser canopy stands intercept more snow than open canopy stands (Telfer 1970; Schaefer and Pruitt 1991), and snow impedes caribou movement and cratering ability (Johnson et al. 2001; Szkorupa 2002).

In addition to canopy cover, we also found that caribou response to forest stands was dependent on stand origin (i.e., natural (fire) versus harvested) and stand height, and differed across herds and between seasons. For example, during early winter, we found that caribou from both herds selected open pine stands $0-14 \mathrm{~m}$ in height but Redrock-Prairie Creek caribou selected harvestorigin stands, whereas Narraway caribou selected natural-origin stands. Yet with increasing canopy 
height, caribou in both herds selected open pine stands regardless of stand origin. For RedrockPrairie Creek caribou, these selection patterns are consistent with findings describing availability of terrestrial lichen in fire-origin versus harvest-origin stands. Initially, after stand disturbance, winter-harvested stands have more terrestrial lichen cover than fire-origin stands (Webb 1998; Coxson and Marsh 2001; Lafleur et al. 2016), but with time terrestrial lichens increase linearly after fire, whereas in harvested stands lichens may decrease approximately 2 years after harvesting (Waterhouse et al. 2011), and abundance can remain low in harvested stands until they reach 30 years old, with peaks in stands between 50 and 100 years old (Coxson and Marsh 2001). Why this pattern was not apparent for Narraway caribou is perhaps because of different availabilities of each habitat type (Table S2), which could influence the availability of terrestrial lichens within each herd.

Although pine stands were generally preferred by Redrock-Prairie Creek caribou during early winter, during late winter we found that Redrock-Prairie Creek caribou preferred natural-origin conifer (i.e., dominated by fir and spruce) stands and avoided open pine stands. In contrast, during late winter Narraway caribou generally selected similar stand types to those selected during early winter. Selection of open conifer (rather than pine) stands during late winter by Redrock-Prairie Creek may be explained by caribou selecting areas with more arboreal lichens when the snow is deep and difficult to crater (Telfer 1970; Schaefer and Pruitt 1991; Szkorupa and Schmiegelow 2003). For Narraway caribou that select spruce stands throughout winter (Saher 2005), fine-scale shifts in foraging and habitat selection between early and late winter may not occur. Nonetheless, our findings using 17 years of data were consistent with previous work using the earliest portion of the GPS dataset (1998-2001; Szkorupa and Schmiegelow 2003; Saher 2005) and further demonstrate the fine-scale behavioural and seasonal differences in habitat use among two herds that can occur within the same designated unit (COSEWIC 2011) and within a small geographic area (e.g., DeCesare et al. 2012; Johnson et al. 2015; Hornseth and Rempel 2016). Moreover, our findings that caribou avoided roads, cutblock edges, and early seral forest stands are also consistent with previous findings and provide further evidence that caribou avoid human disturbance at coarse and fine scales (Schaefer and Mahoney 2007; Polfus et al. 2011; DeCesare et al. 2012; Johnson et al. 2015).

By linking caribou habitat use to forest inventory data, our analysis has provided new and direct links between caribou habitat use and forest stands with different stand origins, species, and canopy cover. Because our motivation for this study was to assess caribou response to stand characteristics described using forest inventory data, we conducted a second-order resource selection function analysis, as previous research found caribou response to forest management was strongest at this scale (DeCesare et al. 2012). Future work assessing caribou habitat use relative to forest inventory data at finer scales (i.e., third order (within the individual home range) and fourth order (patches within the individual home range; Johnson 1980)), perhaps in combination with finer-resolution ecosite data, could provide additional insights into specific stand attributes preferred by caribou and thereby further guide forest management within caribou ranges. Building on previous work with these same herds (Szkorupa 2002; Saher 2005), field data collection at stands used by caribou could also help tease out why particular stands are preferred by caribou over others (sensu Serrouya et al. 2007). Finally, we assessed caribou habitat use during the winter season only, as the seasonal ranges of RedrockPrairie Creek and Narraway caribou overlap most with forests being managed for timber supply during this period. Caribou alter their habitat use across seasons (Polfus et al. 2011; DeCesare et al. 2012) and dependent on their reproductive status (Leblond et al. 2016). In other study areas where caribou inhabit managed forests throughout their annual range, assessing caribou habitat use relative to forest inventory data across multiple seasons, and relative to calving status, will provide a more complete picture of the associations between forest stand attributes and caribou habitat use. 


\section{Conclusions and management applications}

To translate research into management and conservation action, scientists need to provide practitioners with results that are easy to interpret and implement (Arlettaz et al. 2010; Cook et al. 2013). Our results demonstrating that open and closed pine stands and open canopy coniferous stands are selected by caribou throughout winter should be considered by forest managers when planning the timing and location of harvesting in caribou ranges. In addition, as we found that caribou responded differently to natural-origin versus harvest-origin stands of the same height and canopy cover, it is unclear whether harvesting strategies that emulate natural disturbances are perceived by caribou in the same way as natural disturbances. Further work to gauge caribou response to variation in silviculture treatments, cutblock shape, and size will help to evaluate the conservation value of different ecosystem-based management approaches for caribou.

Although previous work found that forest inventory data were relatively poor at predicting wildlife habitat use or attributes associated with quality habitats (McDermid et al. 2009; Boan et al. 2013), results of model selection suggest that combining AVI data with complementary covariates measured at different scales serves to better explain caribou selection behaviour than AVI alone, and that resulting habitat models exhibit excellent predictive power. We are not suggesting that forest inventory data replace satellite-derived habitat data in species models. Indeed, satellite-derived habitat data feature several advantages, especially over large areas, across jurisdictional boundaries, or in protected areas. Nevertheless, since forest inventory data remain a practical and cost-effective means of describing stand structure, forest practitioners are likely to continue to use forest inventory data for planning and management decisions in the near future. To ease interpretation of research results by forest practitioners, scientists should consider building additional models that include forest inventory data or perhaps summarize their final probability surfaces in terms of forest inventory data post-hoc. As new sources become readily available (e.g., LiDAR), the gap between the data used by researchers and forest practitioners may close. In the meantime, however, tailoring results so they are accessible to the end user would help to better facilitate the translation of research into practice.

\section{Acknowledgements}

The study was funded by Weyerhaeuser Co. Ltd., the Foothills Landscape Management Forum (FLMF), and fRI Research. Weyerhaeuser Co. Ltd. and the FLMF provided funds and helped to conceive the project but had no role in study design, data analysis or interpretation, decision to publish, or preparation of this manuscript. fRI Research provided financial and in-kind support for the study design, data analysis, interpretation, and manuscript preparation. We would like to thank Dan Wismer (GIS Program, fRI Research) for help preparing Fig. 1, Alberta Environment and Parks for their continued support of long-term monitoring of Redrock-Prairie Creek and Narraway caribou herds, and Wendy Crosina (Weyerhaeuser Co. Ltd.) and Wayne Thorp (FLMF) for their support of this project. We would also like to thank the anonymous reviewer whose suggestions helped improve this manuscript.

\section{Author contributions}

TDR, DM, and LF conceived and designed the study. TDR and DM performed the experiments/collected the data. TDR and DM analyzed and interpreted the data. TDR, DM, and LF drafted or revised the manuscript.

\section{Competing interests}

The authors have declared that no competing interests exist. 


\section{Data availability statement}

All relevant data are within the paper and in the Supplementary Material.

\section{Supplementary material}

The following Supplementary Material is available with the article through the journal website at doi:10.1139/facets-2018-0050.

Supplementary Material 1

\section{References}

Alberta Sustainable Resource Development. 2005. Alberta Vegetation Inventory interpretation standards. Version 2.1.1. Alberta Sustainable Resource Development, Edmonton, Alberta.

Arlettaz R, Schaub M, Fournier J, Reichlin TS, Sierro A, Watson JEM, et al. 2010. From publications to public actions: when conservation biologists bridge the gap between research and implementation. BioScience, 60(10): 835-842. DOI: 10.1525/bio.2010.60.10.10

Bates D, Maechler M, Bolker B, and Walker S. 2015. Fitting linear mixed-effects models using lme4. Journal of Statistical Software, 61(1): 1-48. DOI: 10.18637/jss.v067.i01

Bergerud A, Ferguson R, and Butler H. 1990. Spring migration and dispersion of woodland caribou at calving. Animal Behaviour, 39(2): 360-368. DOI: 10.1016/S0003-3472(05)80882-6

Bleyhl B, Baumann M, Griffiths P, Heidelberg A, Manvelyan K, Radeloff VC, et al. 2017. Assessing landscape connectivity for large mammals in the Caucasus using Landsat 8 seasonal image composites. Remote Sensing of Environment, 193: 193-203. DOI: 10.1016/j.rse.2017.03.001

Blundell GM, Maier JAK, and Debevec EM. 2001. Linear home ranges: effects of smoothing, sample size, and autocorrelation on kernel estimates. Ecological Monographs, 71(3): 469-489. DOI: 10.1890/0012-9615(2001)071[0469:LHREOS]2.0.CO;2

Boan JJ, McLaren BE, and Malcolm JR. 2013. Predicting non-inventoried forest elements using forest inventory data: the case of winter forage for woodland caribou. Ecoscience, 20(2): 101-111. DOI: $10.2980 / 20-2-3567$

Boyce MS, Vernier PR, Nielsen SE, and Schmiegelow FKA. 2002. Evaluating resource selection functions. Ecological Modelling, 157(2-3): 281-300. DOI: 10.1016/S0304-3800(02)00200-4

Brown GS, Rettie WJ, Brooks RJ, and Mallory FF. 2007. Predicting the impacts of forest management on woodland caribou habitat suitability in black spruce boreal forest. Forest Ecology and Management, 245(1-3): 137-147. DOI: 10.1016/j.foreco.2007.04.016

Brown WK, and Hobson D. 1998. Caribou in west-central Alberta: information review and synthesis. Prepared for the Research Subcommittee of the West-central Alberta Caribou Standing Committee. Terrestrial \& Aquatic Environmental Managers Limited, Calgary, Alberta. $72+$ xi p.

Canadian Council of Forest Ministers. 2014. Statement on forest certification standards in Canada [online]: Available from sfmcanada.org.

Cash DW, Clark WC, Alcock F, Dickson NM, Eckley N, Guston DH, et al. 2003. Knowledge systems for sustainable development. Proceedings of the National Academy of Sciences of the USA, 100(14): 8086-8091. PMID: 12777623 DOI: 10.1073/pnas.1231332100 
Cook CN, Mascia MB, Schwartz MW, Possingham HP, and Fuller RA. 2013. Achieving conservation science that bridges the knowledge-action boundary. Conservation Biology, 27(4): 669-678. PMID: 23574343 DOI: 10.1111/cobi.12050

COSEWIC. 2011. Designatable units for caribou (Rangifer tarandus) in Canada. Committee on the Status of Endangered Wildlife in Canada, Ottawa, Ontario. 88 p.

COSEWIC. 2014. COSEWIC assessment and status report on the caribou (Rangifer tarandus), northern mountain population, central mountain population and southern mountain population in Canada. Committee on the Status of Endangered Wildlife in Canada, Ottawa, Ontario. 113 + xxii p.

Courbin N, Fortin D, Dussault C, and Courtois R. 2009. Landscape management for woodland caribou: the protection of forest blocks influences wolf-caribou co-occurrence. Landscape Ecology, 24(10): 1375-1388. DOI: 10.1007/s10980-009-9389-x

Coxson DS, and Marsh J. 2001. Lichen chronosequences (postfire and postharvest) in lodgepole pine (Pinus contorta) forests of northern interior British Columbia. Canadian Journal of Botany, 79(12): 1449-1464. DOI: 10.1139/b01-127

de Groot RS, Alkemade R, Braat L, Hein L, and Willemen L. 2010. Challenges in integrating the concept of ecosystem services and values in landscape planning, management and decision making. Ecological Complexity, 7(3): 260-272. DOI: 10.1016/j.ecocom.2009.10.006

DeCesare NJ, Hebblewhite M, Robinson HS, and Musiani M. 2010. Endangered, apparently: the role of apparent competition in endangered species conservation. Animal Conservation, 13(4): 353-362. DOI: $10.1111 / \mathrm{j} .1469-1795.2009 .00328 . x$

DeCesare NJ, Hebblewhite M, Schmiegelow F, Hervieux D, McDermid GJ, Neufeld L, et al. 2012. Transcending scale dependence in identifying habitat with resource selection functions. Ecological Applications, 22(4): 1068-1083. PMID: 22827119 DOI: 10.1890/11-1610.1

DeCesare NJ, Hebblewhite M, Bradley M, Hervieux D, Neufeld L, and Musiani M. 2014. Linking habitat selection and predation risk to spatial variation in survival. Journal of Animal Ecology, 83(2): 343-352. PMID: 24099266 DOI: 10.1111/1365-2656.12144

Dussault C, Courtois R, Ouellet J-P, and Huot J. 1999. Evaluation of GPS telemetry collar performance for habitat studies in the boreal forest. Wildlife Society Bulletin, 27(4): 965-972.

Dussault C, Courtois R, Ouellet J-P, and Huot J. 2001. Influence of satellite geometry and differential correction on GPS location accuracy. Wildlife Society Bulletin, 29(1): 171-179.

Edmonds E, and Bloomfield M. 1984. A study of woodland caribou (Rangifer tarandus caribou) in west-central Alberta, 1979-1983. Alberta Energy and Natural Resources Fish and Wildlife Division, Edmonton, Alberta.

Ehlers LPW, Johnson CJ, and Seip DR. 2016. Evaluating the influence of anthropogenic landscape change on Wolf distribution: implications for woodland caribou. Ecosphere, 7(12): e01600. DOI: $10.1002 /$ ecs2.1600

Enquist CAF, Jackson ST, Garfin GM, Davis FW, Gerber LR, Littell JA, et al. 2017. Foundations of translational ecology. Frontiers in Ecology and the Environment, 15(10): 541-550. DOI: 10.1002/fee.1733

Environment Canada. 2012. Recovery strategy for the woodland caribou (Rangifer tarandus caribou), Boreal population, in Canada. Environment Canada, Ottawa, Ontario. xi + 138 p. 
Environment Canada. 2014. Recovery strategy for the woodland caribou, Southern Mountain population (Rangifer tarandus caribou) in Canada. Environment Canada, Ottawa, Ontario. viii + 68 p.

Festa-Bianchet M, Ray JC, Boutin S, Côté SD, and Gunn A. 2011. Conservation of caribou (Rangifer tarandus) in Canada: an uncertain future. Canadian Journal of Zoology, 89(5): 419-434. DOI: $10.1139 /$ z11-025

Fieberg J, Matthiopolus J, Hebblewhite M, Boyce MS, and Frair JL. 2010. Correlation and studies of habitat selection: problem, red herring or opportunity? Philosophical Transactions of the Royal Society B, 365: 2233-2244. DOI: 10.1098/rstb.2010.0079

Fortin D, Courtois R, Etcheverry P, and Dussault C. 2008. Winter selection of landscapes by woodland caribou: behavioural response to geographical gradients in habitat attributes. Journal of Applied Ecology, 45(5): 1392-1400. DOI: 10.1111/j.1365-2664.2008.01542.x

Frair JL, Nielsen SE, Merrill EH, Lele S, Boyce MS, Munro RHM, et al. 2004. Removing GPS collar bias in habitat selection studies. Journal of Applied Ecology, 41: 201-212. DOI: 10.1111/j.00218901.2004.00902.x

Gastón A, Ciudad C, Mateo-Sánchez MC, García-Viñas JI, López-Leiva C, Fernández-Landa A, et al. 2017. Species' habitat use inferred from environmental variables at multiple scales: how much we gain from high-resolution vegetation data? International Journal of Applied Earth Observation and Geoinformation, 55: 1-8. DOI: 10.1016/j.jag.2016.10.007

Gessler P, Chadwick O, Chamran F, Althouse L, and Holmes K. 2000. Modeling soil-landscape and ecosystem properties using terrain attributes. Soil Science Society of America Journal, 64: 2046-2056. DOI: 10.2136/sssaj2000.6462046x

Gillies CS, Hebblewhite M, Nielsen SE, Krawchuk MA, Aldridge CL, Frair JL, et al. 2006. Application of random effects to the study of resource selection by animals. Journal of Animal Ecology, 75(4): 887-898. PMID: 17009752 DOI: 10.1111/j.1365-2656.2006.01106.x

Gillis M, Omule A, and Brierley T. 2005. Monitoring Canada's forests: the National Forest Inventory. The Forestry Chronicle, 81: 214-221. DOI: 10.5558/tfc81214-2

Government of Alberta. 2017. Draft provincial woodland caribou range plan. Government of Alberta, Edmonton, Alberta.

Grimes D, and Schulz K. 2008. Making sense of odds and odds ratios. Obstetrics and Gynecology, 111: 423-426. PMID: 18238982 DOI: 10.1097/01.AOG.0000297304.32187.5d

Gschwantner T, Lanz A, Vidal C, Bosela M, Di Cosmo L, Fridman J, et al. 2016. Comparison of methods used in European National Forest Inventories for the estimation of volume increment: towards harmonisation. Annals of Forest Science, 73(4): 807-821. DOI: 10.1007/s13595-016-0554-5

Hallett LM, Morelli TL, Gerber LR, Moritz MA, Schwartz MW, Stephenson NL, et al. 2017. Navigating translational ecology: creating opportunities for scientist participation. Frontiers in Ecology and the Environment, 15(10): 578-586. DOI: 10.1002/fee.1734

Hervieux D, Hebblewhite M, DeCesare NJ, Russell M, Smith K, Robertson S, et al. 2013. Widespread declines in woodland caribou (Rangifer tarandus caribou) continue in Alberta. Canadian Journal of Zoology, 91: 872-882. DOI: 10.1139/cjz-2013-0123 
Hofmann S, Everaars J, Schweiger O, Frenzel M, Bannehr L, and Cord AF. 2017. Modelling patterns of pollinator species richness and diversity using satellite image texture. PLoS ONE, 12(10): e0185591. PMID: 28973006 DOI: 10.1371/journal.pone.0185591

Hornseth ML, and Rempel RS. 2016. Seasonal resource selection of woodland caribou (Rangifer tarandus caribou) across a gradient of anthropogenic disturbance. Canadian Journal of Zoology, 94(2): 79-93. DOI: 10.1139/cjz-2015-0101

Huang C, Goward SN, Masek JG, Thomas N, Zhu Z, and Vogelmann JE. 2010. An automated approach for reconstructing recent forest disturbance history using dense Landsat time series stacks. Remote Sensing of Environment, 114(1): 183-198. DOI: 10.1016/j.rse.2009.08.017

Hurvich CM, and Tsai C-L. 1989. Regression and time series model selection in small samples. Biometrika, 76(2): 297-307. DOI: 10.1093/biomet/76.2.297

Imbeau L, St-Laurent M-H, Marzell L, and Brodeur V. 2015. Current capacity to conduct ecologically sustainable forest management in northeastern Canada reveals challenges for conservation of biodiversity. Canadian Journal of Forest Research, 45(5): 567-578. DOI: 10.1139/cjfr-2014-0123

Jenness J. 2006. Topographic position index (tpi_jen.avx) extension for ArcView 3.x v. 1.3a. Jenness Enterprises, Flagstaff, Arizona [online]: Available from jennessent.com/arcview/tpi.htm.

Johnson CJ, Parker K, and Heard D. 2001. Foraging across a variable landscape: behavioral decisions made by woodland caribou at multiple spatial scales. Oecologia, 127(4): 590-602. PMID: 28547497 DOI: $10.1007 / \mathrm{s} 004420000573$

Johnson CJ, Parker K, and Heard D. 2003. Characterizing woodland caribou habitat in sub-boreal and boreal forests. Forest Ecology and Management, 180: 241-248. DOI: 10.1016/S0378-1127(02)00563-7

Johnson CJ, Ehlers LPW, and Seip DR. 2015. Witnessing extinction-cumulative impacts across landscapes and the future loss of an evolutionarily significant unit of woodland caribou in Canada. Biological Conservation, 186: 176-186. DOI: 10.1016/j.biocon.2015.03.012

Johnson D. 1980. The comparison of usage and availability measurements for evaluating resource preference. Ecology, 61(1): 65-71. DOI: 10.2307/1937156

Lafleur B, Zouaoui S, Fenton NJ, Drapeau P, and Bergeron Y. 2016. Short-term response of Cladonia lichen communities to logging and fire in boreal forests. Forest Ecology and Management, 372: 44-52. DOI: 10.1016/j.foreco.2016.04.007

Latham ADM, Latham MC, Boyce MS, and Boutin S. 2013. Spatial relationships of sympatric wolves (Canis lupus) and coyotes (C. latrans) with woodland caribou (Rangifer tarandus caribou) during the calving season in a human-modified boreal landscape. Wildlife Research, 40(3): 250-260. DOI: $10.1071 / \mathrm{WR} 12184$

Leblond M, Frair J, Fortin D, Dussault C, Ouellet J-P, and Courtois R. 2011. Assessing the influence of resource covariates at multiple spatial scales: an application to forest-dwelling caribou faced with intensive human activity. Landscape Ecology, 26(10): 1433-1446. DOI: 10.1007/s10980-011-9647-6

Leblond M, Dussault C, Ouellet J-P, and St-Laurent M-H. 2016. Caribou avoiding wolves face increased predation by bears-caught between Scylla and Charybdis. Journal of Applied Ecology, 53(4): 1078-1087. DOI: $10.1111 / 1365-2664.12658$ 
Lewis JS, Rachlow JL, Garton EO, and Vierling LA. 2007. Effects of habitat on GPS collar performance: using data screening to reduce location error. Journal of Applied Ecology, 44: 663-671. DOI: $10.1111 / j .1365-2664.2007 .01286 . x$

Losier CL, Couturier S, St-Laurent MH, Drapeau P, Dussault C, Rudolph T, et al. 2015. Adjustments in habitat selection to changing availability induce fitness costs for a threatened ungulate. Journal of Applied Ecology, 52(2): 496-504. DOI: 10.1111/1365-2664.12400

MacNearney D, Pigeon K, Stenhouse G, Nijland W, Coops N, and Finnegan L. 2016. Heading for the hills? Evaluating spatial distribution of woodland caribou in response to a growing anthropogenic disturbance footprint. Ecology and Evolution, 6(18): 6484-6509. PMID: 27777724 DOI: $10.1002 /$ ece 3.2362

Margules CR, and Pressey RL. 2000. Systematic conservation planning. Nature, 405: 243-253. PMID: 10821285 DOI: $10.1038 / 35012251$

Maxie AJ, Hussey KF, Lowe SJ, Middel KR, Pond BA, Obbard ME, et al. 2010. A comparison of forest resource inventory, provincial land cover maps and field surveys for wildlife habitat analysis in the Great Lakes-St. Lawrence forest. The Forestry Chronicle, 86(1): 77-86. DOI: 10.5558/tfc86077-1

McDermid GJ, Hall RJ, Sanchez-Azofeifa GA, Franklin SE, Stenhouse GB, Kobliuk T, et al. 2009. Remote sensing and forest inventory for wildlife habitat assessment. Forest Ecology and Management, 257(11): 2262-2269. DOI: 10.1016/j.foreco.2009.03.005

McLaren BE, and Mahoney SP. 2001. Comparison of forestry-based remote sensing methodologies to evaluate woodland caribou habitat in non-forested areas of Newfoundland. The Forestry Chronicle, 77(5): 866-873.

McLoughlin PD, Morris DW, Fortin D, Vander Wal E, and Contasti AL. 2010. Considering ecological dynamics in resource selection functions. Journal of Animal Ecology, 79(1): 4-12. PMID: 19732211 DOI: $10.1111 / j .1365-2656.2009 .01613 . x$

Neufeld LM. 2006. Spatial dynamics of wolves and woodland caribou in an industrial forest landscape in west-central Alberta. M.Sc. thesis, University of Alberta, Edmonton, Alberta. 155 p.

Nielsen SE, Cranston J, and Stenhouse GB. 2009. Identification of priority areas for grizzly bear conservation and recovery in Alberta, Canada. Journal of Conservation Planning, 5: 38-60.

Northrup JM, Hooten MB, Anderson CRJ, and Wittemyer G. 2013. Practical guidance on characterizing availability in resource selection functions under a use-availability design. Ecology, 94(7): 1456-1463. PMID: 23951705 DOI: 10.1890/12-1688.1

Päivinen R, Van Brusselen J, and Schuck A 2009. The growing stock of European forests using remote sensing and forest inventory data. Forestry, 82(5): 479-490. DOI: 10.1093/forestry/cpp017

Polfus JL, Hebblewhite M, and Heinemeyer K. 2011. Identifying indirect habitat loss and avoidance of human infrastructure by northern mountain woodland caribou. Biological Conservation, 144(11): 2637-2646. DOI: 10.1016/j.biocon.2011.07.023

Pressey RL, Cabeza M, Watts ME, Cowling RM, and Wilson KA. 2007. Conservation planning in a changing world. Trends in Ecology \& Evolution, 22(11): 583-592. DOI: 10.1016/j.tree.2007.10.001 
R Development Core Team. 2017. R: a language and environment for statistical computing. R Foundation for Statistical Computing, Vienna, Austria [online]: Available from R-project.org/.

Rudolph TD, and Drapeau P. 2012. Using movement behaviour to define biological seasons for woodland caribou. Rangifer, 32(2): 295-307. DOI: 10.7557/2.32.2.2277

Saher DJ. 2005. Woodland caribou habitat selection during winter and along migratory routes in west-central Alberta. M.Sc. thesis, University of Alberta, Edmonton, Alberta. 125 p.

Saher DJ, and Schmiegelow FKA. 2005. Movement pathways and habitat selection by woodland caribou during spring migration. Rangifer, 25(4): 143-154. DOI: 10.7557/2.25.4.1779

Schaefer JA, and Mahoney SP. 2007. Effects of progressive clearcut logging on Newfoundland caribou. Journal of Wildlife Management, 71(6): 1753-1757. DOI: 10.2193/2005-479

Schaefer JA, and Pruitt WOJ. 1991. Fire and woodland caribou in southeastern Manitoba. Wildlife Monographs, 116: 3-39.

Serrouya R, McLellan BN, and Flaa JP. 2007. Scale-dependent microhabitat selection by threatened mountain caribou (Rangifer tarandus caribou) in cedar-hemlock forests during winter. Canadian Journal of Forest Research, 37(6): 1082-1092. DOI: 10.1139/X06-279

Sheather SJ, and Jones MC. 1991. A reliable data-based bandwidth selection method for kernel density estimation. Journal of the Royal Statistical Society: Series B (Statistical Methodology), 53(3): 683-690. DOI: 10.1111/j.2517-6161.1991.tb01857.x

Slater SC. 2013. Woodland caribou conservation in Alberta: range delineation and resource selection. M.Sc. thesis, University of Alberta, Edmonton, Alberta. 151 p.

Smith KG, Ficht EJ, Hobson D, Sorensen TC, and Hervieux D. 2000. Winter distribution of woodland caribou in relation to clear-cut logging in west-central Alberta. Canadian Journal of Zoology, 78: 1433-1440. DOI: 10.1139/z00-094

Sutherland WJ, Fleishman E, Mascia MB, Pretty J, and Rudd MA. 2011. Methods for collaboratively identifying research priorities and emerging issues in science and policy. Methods in Ecology and Evolution, 2(3): 238-247. DOI: 10.1111/j.2041-210X.2010.00083.x

Szkorupa TD. 2002. Multi-scale habitat selection by mountain caribou in west-central Alberta. M.Sc. thesis, University of Alberta, Edmonton, Alberta. 92 p.

Szkorupa TD, and Schmiegelow F. 2003. Multi-scale habitat selection by mountain caribou in West Central Alberta. Rangifer, 23(5): 293-294. DOI: 10.7557/2.23.5.1712

Telfer E. 1970. Winter habitat selection by moose and white-tailed deer. Journal of Wildlife Management, 34: 553-559. DOI: 10.2307/3798862

Tucker MA, Böhning-Gaese K, Fagan WF, Fryxell JM, Van Moorter B, Alberts SC, et al. 2018. Moving in the Anthropocene: global reductions in terrestrial mammalian movements. Science, 359(6374): 466-469. PMID: 29371471 DOI: 10.1126/science.aam9712

Vitt DH, Marsh JE, and Bovey R. 1988. Mosses, lichens \& ferns of Northwest North America. Lone Pine Publishing, Edmonton, Alberta. 296 p.

Vors LS, and Boyce MS. 2009. Global declines of caribou and reindeer. Global Change Biology, 15(11): 2626-2633. DOI: 10.1111/j.1365-2486.2009.01974.x 
Warren SD, Alt M, Olson KD, Irl SDH, Steinbauer MJ, and Jentsch A. 2014. The relationship between the spectral diversity of satellite imagery, habitat heterogeneity, and plant species richness. Ecological Informatics, 24: 160-168. DOI: 10.1016/j.ecoinf.2014.08.006

Waterhouse MJ, Armleder HM, and Nemec AFL. 2011. Terrestrial lichen response to partial cutting in lodgepole pine forests on caribou winter range in west-central British Columbia. Rangifer, 31(2): 119-134. DOI: 10.7557/2.31.2.1996

Webb ET. 1998. Survival, persistence, and regeneration of the reindeer lichens, Cladina stellaris, C. rangiferina, and C. mitis following clearcut logging and forest fire in northwestern Ontario. Rangifer, 18(5): 41-47. DOI: 10.7557/2.18.5.1440

Weichselgartner J, and Kasperson R. 2010. Barriers in the science-policy-practice interface: toward a knowledge-action-system in global environmental change research. Global Environmental Change, 20(2): 266-277. DOI: 10.1016/j.gloenvcha.2009.11.006

Wickham H. 2016. ggplot2: elegant graphics for data analysis. Springer-Verlag, New York, New York.

Zuur AF, Ieno EN, Walker N, Saveliev AA, and Smith GM. 2009. Mixed effects models and extension in ecology with R. Springer-Verlag, New York, New York. 574 p.

Zuur AF, Ieno EN, and Elphick CS. 2010. A protocol for data exploration to avoid common statistical problems. Methods in Ecology and Evolution, 1(1): 3-14. DOI: 10.1111/j.2041-210X.2009.00001.x 